\title{
Detecting Nestmate Recognition Patterns in the Fission-Performing Ant Aphaenogaster senilis: A Comparison of Different Indices
}

\author{
Katsuya Ichinose, , 2,4 Xím Cerdá, ${ }^{1,3}$ Christidès Jean-Philippe, ${ }^{1}$ \\ and Alain Lenoir ${ }^{1}$
}

In this paper, we compare three indices for nestmate recognition behaviors in the ant Aphaenogaster senilis within and among colonies and populations: the classical Aggression Index, a multidimensional Principal Component Analysis (PCA) Behavioral Index incorporating all observed behaviors, and a Chemical Profile Index for cuticular hydrocarbon composition. With these indices, we quantified nestmate recognition behaviors between workers from a parent nest and between those from independent colonies. The PCA Behavioral Index performed as well as or better than the classical Aggression Index in distinguishing small differences in nestmate recognition. Correlation analysis of the PCA Behavioral Index with the Chemical Profile Index may assist in identifying the occurrence of colony fissions. The PCA Behavioral Index correlated strongly with the Chemical Profile Index, suggesting that hydrocarbon profiling may be used as an alternative to nestmate recognition assays. This correlation also suggests that nestmate recognition in A. senilis is a graded response rather than a threshold one.

KEY WORDS: aggression; ant; budding; cuticular hydrocarbon profile; nestmate recognition.

\footnotetext{
${ }^{1}$ IRBI Institut de Recherche de Biologie de l'Insecte, Faculté des Sciences et Techniques, Université François Rabelais Tours, CNRS UMR 6035, Parc de Grandmont, 37200 Tours, France.

${ }^{2}$ Okinawa Subtropical Station of Japan International Research Centre for Agricultural Sciences, Maesato Kawarabaru 1091-1, Ishigaki, Okinawa-ken 907-0002, Japan.

${ }^{3}$ Departamento de Biología Evolutiva, Estación Biologica de Doñana, CSIC, Apdo. 1056 E-41080 Sevilla, Spain.

${ }^{4}$ To whom correspondence should be addressed. E-mail: ichis@affrc.go.jp.
} 


\section{INTRODUCTION}

Since Crozier and Dix (1979) proposed the individualistic and Gestalt models for nestmate recognition in social insects, nestmate recognition has been widely studied in various social insects. The Gestalt model is commonly supported in species that establish larger colonies (Carlin and Hölldobler, 1986; Dahbi et al., 1997; Lenoir et al., 2001c), while the individualistic model is generally supported in species such as primitive ponerine ants, which establish small colonies (Soroker et al., 2003). Recognition behaviors are presumably determined by the spectrum of cuticular hydrocarbons (Vander Meer and Morel, 1998; Lenoir et al., 2001b). A nest-specific spectrum of odors, termed the "gestalt," is generated. The gestalt odor is established through hydrocarbons regurgitated from the postpharyngeal gland (Soroker et al., 1994; Lahav et al., 1999, 2001) and exchanged with other colony members by allo-grooming, trophallaxis, or body touching (Dahbi et al., 1999; Boulay et al., 2000; Lenoir et al., 2001a; Boulay et al., 2004; see also Blomquist and Howard, 2003). Each member of the colony learns this common odor as an internal representation called the "template." When encountering another insect, she compares the odor of encountered animals with her template to determine if it belongs to her colony.

There are two possible models for the responses of ants encountering odors different from the template. The threshold model (Reeve, 1989) predicts that if the difference between the template and the encountered odor spectrum is above a threshold, the insects will behave aggressively. According to the threshold model, the aggression based on the chemical profile will be an "all-or-none" response. The graded model, on the other hand, proposes that ants may vary their level of aggression according to the difference between the template and the encountered odors (Lenoir et al., 1999; see also Cassill and Tschinkel, 1999). Thus, a linear regression is expected under the graded model if both behavior and the chemical profile difference are properly quantified.

The classical Aggression Index defines the degree of nestmate recognition by scoring individual aggressive behaviors (e.g., Carlin and Hölldobler, 1987; Hefetz et al., 1996; Stuart and Herbers, 2000, Roulston et al., 2003). The Aggression Index may not correctly scale intermediate levels of recognition such as those found in ants that perform nest fission. Colony fission is when a social insect colony divides into new colonies and it is different from "budding," which occurs in polygynous societies (Bourke and Franks, 1995). Worker recognition responses between the two fissioning nests gradually alter, from peaceful to "skeptic" to aggressive over time (e.g., Dahbi and Lenoir, 1998; Boulay et al., 2000; Lahav et al., 2001, 2001c). For such species, multi-dimensional statistical methods in which all behaviors are incorporated, such as the Principal Component Analysis (PCA), might be 
used. We first compared the primary component of PCA with the classical Aggression Index using Aphaenogaster senilis Mayr (Myrmicinae), an ant species that exhibits nest fission. In this species, a group of workers leave the mother colony with small larvae that develop into gynes under the queenless condition, one of which then becomes the queen of the new daughter colony (Ledoux, 1971).

Chemical profiles are more easily quantified than behavior. They are evaluated as an assembly of cuticular hydrocarbons detected by gas chromatograph analyses. The Nei's index for genetic relatedness, mathematically equivalent to the Pianka's diversity index for niche overlap between two species (c.f. Krebs, 1989), is often used (Hughes et al., 2001; Lenoir et al., 1997, 2001a, de Biseau et al., 2004). A robust index is the Mahalanobis distance obtained by discriminant analysis (Lenoir et al., 2001a; see also Singer et al., 1992). We compared these indices to find which index would best reflect the results of behavioral observation. We hypothesized that carefully chosen behavioral and chemical profile indices would be linearly regressed. Such a regression could help detect fissional nests derived from the same colony; as ants in these nests alter their behavior gradually over time as their chemical profiles diverge (Boulay and Lenoir, 2001; Lenoir et al., 2001a). The period of separation of a pair of nests could be estimated by the location of the pair in question on the regression plot.

For the determination of these indices, we used laboratory-maintained colonies of $A$. senilis provided with the same food and nest materials in order to reduce the influence of environmental factors on both the behavioral and chemical profiles as much as possible (see Dahbi et al., 1996; Thomas et al., 1999: Chen and Nonacs, 2000; Liang and Silverman, 2000; Stuart and Herbers, 2000; Liang et al., 2001; Silverman and Liang, 2001). We then applied the indices to field-collected colonies of $A$. senilis separated by distances ranging from several meters to $370 \mathrm{~km}$ and examined the influences of both the geographical and spatial distributions on recognition behaviors. Taking into account negative correlation of geographic distance and genetic relatedness among colonies (Beye et al., 1998; Nielsen et al., 1999), we discuss the influence of the genetic conditions on the recognition through chemical profile.

\section{MATERIALS AND METHODS}

\section{Ants for Experiments}

We used 11 colonies that had been collected in 1999 from two locations of about $12 \mathrm{~km}$ distance in Spain: Doñana National Park in Andalusia (designated as 1-10) and Palomares in Jaen Province (11). The colonies were 
kept in the laboratory (temperature $21-28^{\circ} \mathrm{C}$, humidity $20-50 \%$, 11L13D). The ants were given live calliphoride larvae three times a week and honey and orange pieces once a week.

We also collected 19 nests of $A$. senilis (1-19) in May 2002 in an area of about $150 \mathrm{~m} \times 150 \mathrm{~m}$ in Doñana. The collected nests were distinguished into three groups (I, II, and III) on a spatial distribution map according to their relatively short internidal distances (Fig. 1). We collected an additional two nests (20-21) from another area about $2 \mathrm{~km}$ from the first and two more nests (22-23) from the mountain area of the Sierra Nevada in Grenada, located ca. $370 \mathrm{~km}$ from Doñana. These nests were maintained in the laboratory as described earlier. Because of the species fissioning activity (Ledoux, 1971), some collected nests could have originally belonged to the same colony. However, since we could not confirm behavioral connection between nests at the collection time, we treated the nests as independent colonies.

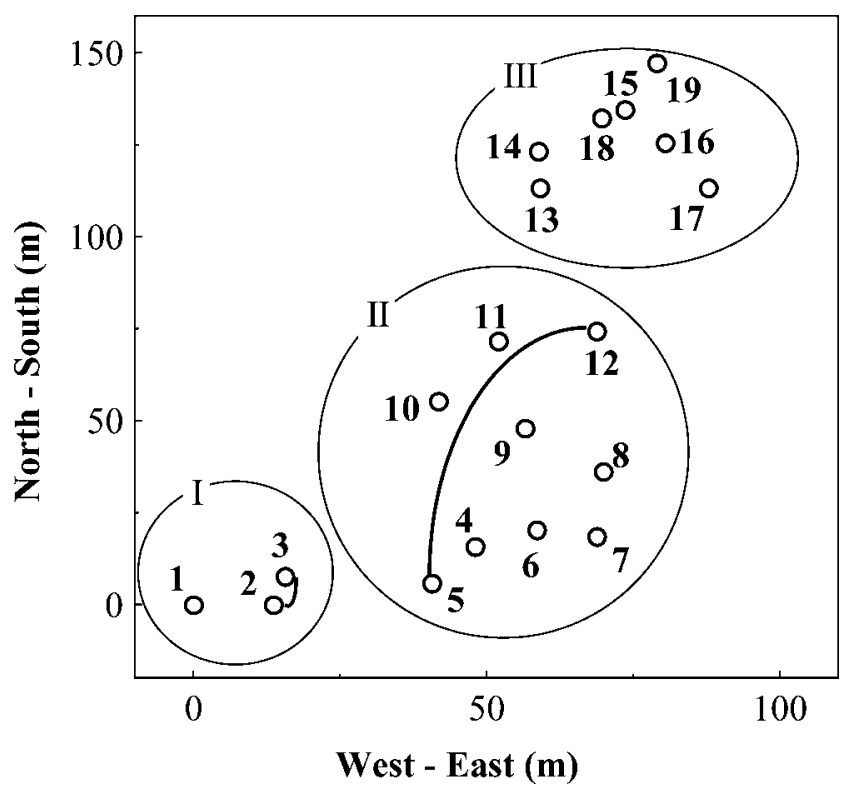

Fig. 1. Distribution map of Aphaenogaster senilis nests in Doñana, southern Spain. Nests that were distributed over relatively short distances were grouped (I-III) and enclosed by circles. Nests that were suggested to have been in a fissioning-mother nest relationship are connected by thick lines. 


\section{Behavioral Observations}

Observations of the laboratory colonies were conducted from October 2001 to January 2002. Colonies were paired, e.g., A and B (AB pair), and distinguished from the reciprocal pair, BA, because colony aggressiveness could vary. Three sub-pairs were made for each pair to examine the possible effects of polyethism. For example, we tested (1) three A foragers with one B forager; (2) three A foragers with one B nurse; (3) three A nurses with one B nurse. These workers were chosen randomly and painted on the thorax or abdomen so that the origin of their colonies could be identified during observation. Any one worker was used only once in a given replicate of a given pair. The homo-colonial pair (AA) was tested as a control. Likewise, BA and BB were tested. All possible colony pairs were examined for a total of 330 homo-colonial combinations and 330 allo-colonial combinations.

For a given sub-pair, e.g., $\mathrm{AB}$, three $\mathrm{A}$ workers were placed in a transparent plastic box ( $50 \mathrm{~mm}$ in diameter and $54 \mathrm{~mm}$ in height), and the $B$ worker was placed in another box for $10 \mathrm{~min}$ to be accustomed to the experimental conditions. Then the B worker was introduced into the box with the A workers. All behaviors between the B worker and any of the A workers were recorded for $30 \mathrm{~min}$ starting from the time of release. The behaviors observed within the first 10 min were used for the present study, as our preliminary analyses on behavior indicated that the observation time could be reduced to $10 \mathrm{~min}$ without losing pertinent information. We distinguished four categories of behaviors: resting motionlessly side by side with at least one of the A workers, antennal contact, allo-grooming, and aggression. Aggression included threatening by opening the mandibles, seizing or biting the opponent's body, and fighting. Quick avoiding or escaping from the opponent is reported as a response to strangers in formicine ants, Camponotus spp. (e.g., Carlin and Hölldobler, 1987). This behavior was excluded from the present study, although possible quick avoidances were observed. This was due both to difficulty in strictly distinguishing this behavior from ants swiftly passing by each other and to an expectation that the avoiding behavior in a colony pair, if any, would reduce the occurrences of other behaviors to such a level that the pair could be distinguished from the others. The latency until the release of the first aggression (aggression latency) was used as the fifth category. In replicates where no aggression was observed for $10 \mathrm{~min}$, the duration of aggression latency was taken as $10 \mathrm{~min}$. The frequency of each behavior and the aggression latency were standardized for each category (thus each variable had a mean of 0 and a SD of 1) and analyzed by MANOVA with respect to the colony, the confrontation category (homo- or allo-colonial) and the worker class (forager or nurse). 
A Principal Component Analysis (PCA) was performed on the standardized values in each variable. The first component contributed $39.7 \%$ of the total variation, and this component was used as a behavioral index (PCA Behavioral Index).

By giving a score of (1) to opening of mandibles and (2) to biting and fighting, the Aggression Index $(A)$ was calculated for each sub-pair by the following equation:

$$
A=[(\text { op } \times 1)+(b f \times 2)] / n,
$$

where $n$ is the total number of behaviors, op the number of opening mandibles, and bf the number of biting or fighting. Finally, the means of both the PCA Behavioral and Aggression Indices of each pair were finally used to quantify worker behavior of AB.

Similar observations were made for field-collected colonies. In these observations, colonies were randomly paired within each group in Fig. 1 (intra-group), between groups (inter-group), between colonies in Fig. 1 and those in the other area of Doñana (inter-habitat), and between colonies in Fig. 1 and those in Grenada (inter-population): 15 intra-colonial pairs; 15 inter-colonial intra-group; 12 inter-colonial inter-group; 12 inter-colonial inter-habitat; and 12 inter-population. No reciprocal pairs, e.g., 6-5 for 5-6 were tested.

\section{Cuticular Hydrocarbons Profile}

Cuticular hydrocarbon profiles of both laboratory and field colonies were analyzed with gas chromatography. For the laboratory colonies, three foragers and three nurses were randomly taken from individual colonies. For the field colonies, three workers were randomly taken from the box of each nest. The thorax with the legs of each worker was immersed in $1 \mathrm{ml}$ of pentane for $5 \mathrm{~min}$. The extract was left in the laboratory at $22-28^{\circ} \mathrm{C}$ until the pentane was evaporated, and then kept at $-21^{\circ} \mathrm{C}$ until analysis. When analyzed, the extract was re-dissolved in $50 \mu \mathrm{l}$ of pentane containing $50 \mathrm{ng}$ of $\mathrm{C}_{20}$ as an internal standard. Five microliter of the dissolved extract was then applied to gas chromatography (VGM250Q coupled with a TurboChrome Workstation) using a DB-5 fused silica capillary column. Temperatures were programmed to be kept at $150^{\circ} \mathrm{C}$ in the initial $2 \mathrm{~min}$, increased at $150-300^{\circ} \mathrm{C}$ at $5^{\circ} \mathrm{C} / \mathrm{min}$ for the following $30 \mathrm{~min}$ and kept at $300^{\circ} \mathrm{C}$ for the last $12 \mathrm{~min}$. Hydrocarbons were identified according to Lenoir et al. (2001a). Some of the peaks were pooled because of their small quantity, making 25 quantifiable peaks. Each substance or group of substances was quantified by peak integration in comparison to the internal standard, and 
the percent proportions of individual peaks to the total amount was calculated for each worker.

The Pianka's index, $O_{j k}$, was calculated to evaluate similarity of HCs profiles between any two colonies as follows (Krebs, 1989):

$$
O_{j k}=\frac{{ }^{n} p_{i j} p_{i k}}{-{ }^{n} p_{i j}^{2}-{ }^{n} p_{i k}^{2}},
$$

where $p_{i j}$ and $p_{i k}$ designate the proportion of the $i$ th peak in the $j$ worker and that of the $k$ th worker, respectively. The total number of peaks is designated by $(n=25)$. A discriminant analysis on the HCs proportions in individual workers was performed among 22 groups combining the origin of colony (11) and worker class (2, forager or nurse), and the Mahalanobis distance was used as another index for the chemical profile (Chemical Profile Index).

The effect of worker age on behavior and chemical profile was examined by a split-plot design using laboratory colonies, in which six categories were made in combination with the pair of colonies (same or different): a forager with foragers from the same colony pair (forager/forager/ same); forager/nurse/same; nurse/nurse/same; forager/nurse/different; forager/forager/different; and nurse/nurse/different. The aforementioned effects were tested by ANOVA for these categories.

\section{RESULTS}

\section{Behavioral Indices of Laboratory Colonies}

A total of 5928 behaviors were observed. Worker behavior was different (1) between colonies, (2) between homo- and allo-colonial confrontations, and (3) between foragers and nurses (Table I), indicating that workers' recognition behaviors were influenced both by their age, genuine conditions of their colonies, and external conditions carried by encounters.

Worker recognition behavior differed both between homo- and allocolonial pairs and between colonies (Fig. 2). Neither the PCA Behavioral Index nor Aggression Index of the homo-colonial pairs were significantly different among the colonies (ANOVA: $F_{10,390}=0.929, P=0.506$; $F_{10,390}=0.726, P=0.700$, respectively), while both indices of the allocolonial pairs were significantly different among colonies $\left(F_{10,390}=3.209\right.$, $\left.P=0.001 ; F_{10,390}=4.283, P<0.001\right)$. The PCA Behavioral and Aggression Indices did not differ among colonies, except the colony 7 which was significantly different from the other colonies (Fig. 2, Newman-Keuls test, $P<0.05)$. 
Table I. Results of MANOVA Performed on the Five Behavioral Categories in Worker Pairs to Detect the Effects of the Colony, the Homo- and Allo-Colonial Pairs of Workers and the Combination of Worker Classes in the Pair (Forager/Forager, Forager/Nurse and Nurse/Nurses)

\begin{tabular}{lcccc}
\hline & & \multicolumn{3}{c}{ One worker } \\
\cline { 3 - 5 } \multicolumn{1}{c}{ Factor } & $d f$ & Pillai’s trace & $F$ & $P$ \\
\hline Colony & 40,2372 & 0.175 & 2.717 & $<0.001$ \\
Pair & 4,590 & 0.660 & 286.9 & $<0.001$ \\
Class & 8,1182 & 0.070 & 5.357 & $<0.001$ \\
Colony $\times$ pair & 30,2372 & 0.123 & 1.882 & 0.001 \\
Colony $\times$ class & 80,2372 & 0.152 & 1.170 & 0.146 \\
Pair $\times$ class & 8,1182 & 0.012 & 0.862 & 0.548 \\
Colony $\times$ pair $\times$ class & 80,2372 & 0.147 & 1.130 & 0.205 \\
\hline
\end{tabular}

Both the PCA Behavioral and Aggression Indices were significantly influenced by the origin of the colonies and by worker class $\left(F_{5,645}=\right.$ 93.119, $P<0.001 ; F_{5,645}=92.954, P<0.001$, respectively) (Table II). The PCA Behavioral Index was not significantly different among the allocolonial pairs (Newman-Keuls test, $P>0.05$ ), but a significant difference was found in the homo-colonial pairs: the foragers/nurse pairing and the other two categories (foragers/foragers, nurses/nurse) differed significantly. The Aggression Index, on the other hand, was not significantly different in the homo-colonial pairings, but the forager/nurse category was significantly different from the other two categories in the allo-colonial pairings. These results indicate that (1) behaviors were different between foragers and nurses, and (2) the PCA Behavioral Index better distinguished behaviors between nestmates than the Aggression Index, whereas the latter better distinguished between non-nestmates than the PCA Behavioral Index.

\section{Behavioral Indices of Field-Collected Colonies}

The PCA Behavioral and Aggression Indices of field-collected colonies were much lower in intranidal pairings than in the other categories (Fig. 3, ANOVA: $\left.F_{4,193}=56.001, P<0.001\right)$. Among the categories intraand inter-group, inter-habitat and inter-populations, significant differences were observed for the PCA Behavioral Index, indicating an increase of discrimination with the distance between nests (Neuman-Keuls test at $P=$ 0.05). No significant differences were detected with the Aggression Index (same test, $P>0.05$ ). 

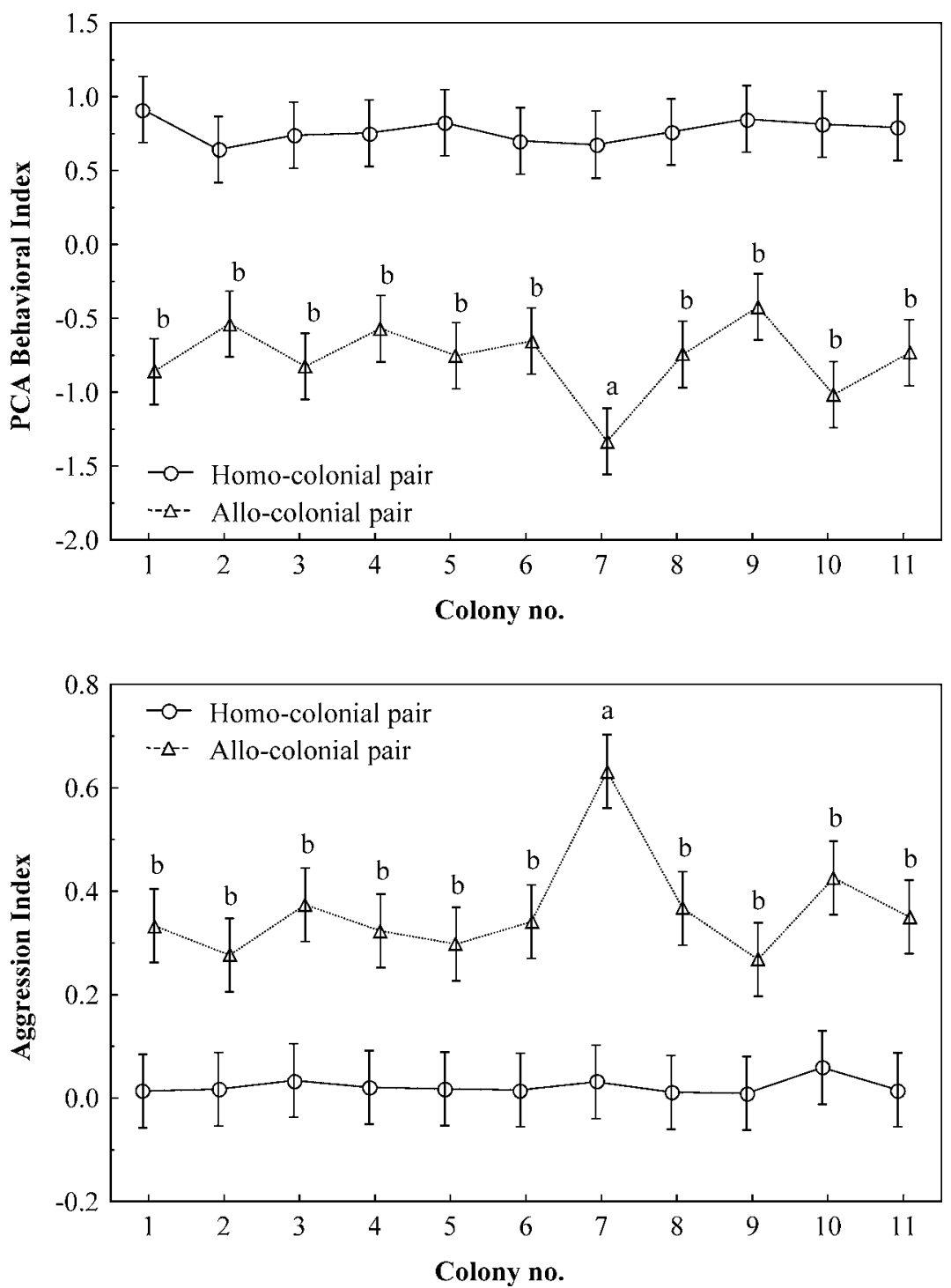

Fig. 2. The PCA Behavioral and Aggression Indices (mean \pm SD) in the homo- (circles) and allo-colonial pairs (triangles) for laboratory colonies. The same letters indicate no significant difference at $P>0.05$ by Newman-Keuls tests in different colony pairs. No significant differences were detected among the homo-colonial pairs. 
Table II. PCA Behavioral and Aggression Indices and Chemical Profile Index of Workers in the Six Categories Combining the Colony Pair and Worker Classes: Forager with Forager of Homo-Colonial Pair (Same); Nurse/Nurse/Same; Forager/Nurse/Same; Forager/Nurse/Different; Forager/Forager/Different; and Nurse/Nurse/Different

\begin{tabular}{|c|c|c|c|c|c|c|}
\hline \multirow[b]{2}{*}{ Worker/worker/colony } & \multicolumn{2}{|c|}{ PCA Behavioral Index } & \multicolumn{2}{|c|}{ Aggression Index } & \multicolumn{2}{|c|}{ Chemical Profile Index } \\
\hline & $n$ & Mean $\pm \mathrm{SD}^{a}$ & $n$ & Mean $\pm \mathrm{SD}^{a}$ & $n$ & Mean $\pm \mathrm{SD}^{a}$ \\
\hline Forager/forager/same & 110 & $0.856 \pm 0.423 a$ & 110 & $0.015 \pm 0.072 \mathrm{a}$ & 11 & $15.6 \pm 4.8 \mathrm{a}$ \\
\hline Forager/nurse/same & 110 & $0.643 \pm 0.514 b$ & 110 & $0.046 \pm 0.134 a$ & 22 & $86.4 \pm 42.4 \mathrm{~b}$ \\
\hline Nurse/nurse/same & 110 & $0.804 \pm 0.466 a$ & 110 & $0.007 \pm 0.038 a$ & 11 & $17.8 \pm 5.8 \mathrm{a}$ \\
\hline Nurse/nurse/different & 110 & $-0.842 \pm 0.734 \mathrm{c}$ & 110 & $0.414 \pm 0.288 b$ & 22 & $209.2 \pm 143.1 \mathrm{c}$ \\
\hline Forager/forager/different & 110 & $-0.705 \pm 0.784 c$ & 110 & $0.337 \pm 0.261 c$ & 11 & $209.9 \pm 97.0 c$ \\
\hline Forager/nurse/different & 110 & $-0.756 \pm 0.792 \mathrm{c}$ & 110 & $0.336 \pm 0.279 c$ & 11 & $212.1 \pm 184.8 \mathrm{c}$ \\
\hline
\end{tabular}

${ }^{a}$ The same letters in each index indicate no significant difference at $P>0.05$ by Newman-Keuls tests after arcsine transformation for the PCA Behavioral and Aggression Indices and log-transformation for the Chemical Profile Index. 


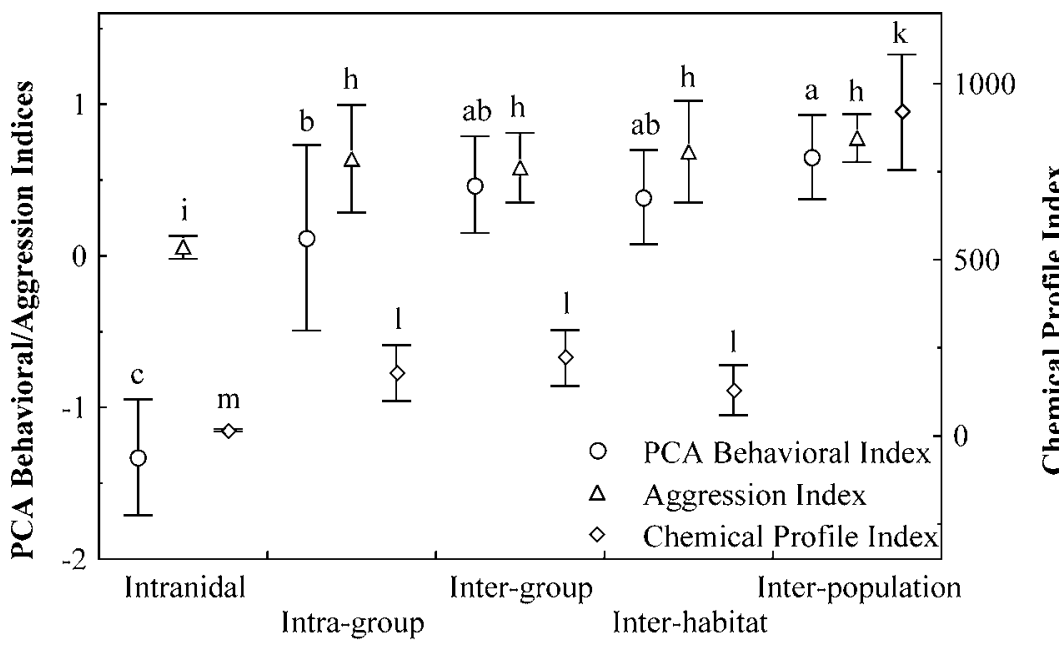

Colony pair

Fig. 3. The means of PCA Behavioral (circles) and Aggression (triangles) Indices for worker behaviors and Chemical Profile Index in five colony groups: intranidal pair and internidal intra-group, inter-group, inter-habitat and inter-population pairs. See also Fig. 1 for the definition of these groups.

\section{Hydrocarbon Profile Indices}

The Pianka's index did not clearly separate the homo- or allo-colonial pairs of laboratory colonies as the Chemical Profile Index did (Fig. 4). The Chemical Profile Index was significantly different among laboratory colonies, and the results by a multiple comparison test on the index corresponded to that of the PCA Behavioral Index and not to the Aggression Index (Table II). In particular, the Chemical Profile Index of the allo-colonial pairs of colony 7 was significantly different from the others (Newman-Keuls test, $P<0.05$ ), corresponding to the findings of the PCA Behavioral Index. Therefore, we chose to use the PCA Behavioral Index. The Chemical Profile Index was also significantly different among the four groups of field colonies (ANOVA after log-transformation: $F_{3,47}=100.91, P<0.001$ ). No significant differences were detected between the intra-group, intergroup and inter-habitat categories, but the difference between these categories and the inter-population category was significant (Newman-Keuls test, $P<0.05$ ).

In both laboratory and field colonies, PCA Behavioral and Aggression Indices were significantly linearly regressed on the log-transformed 

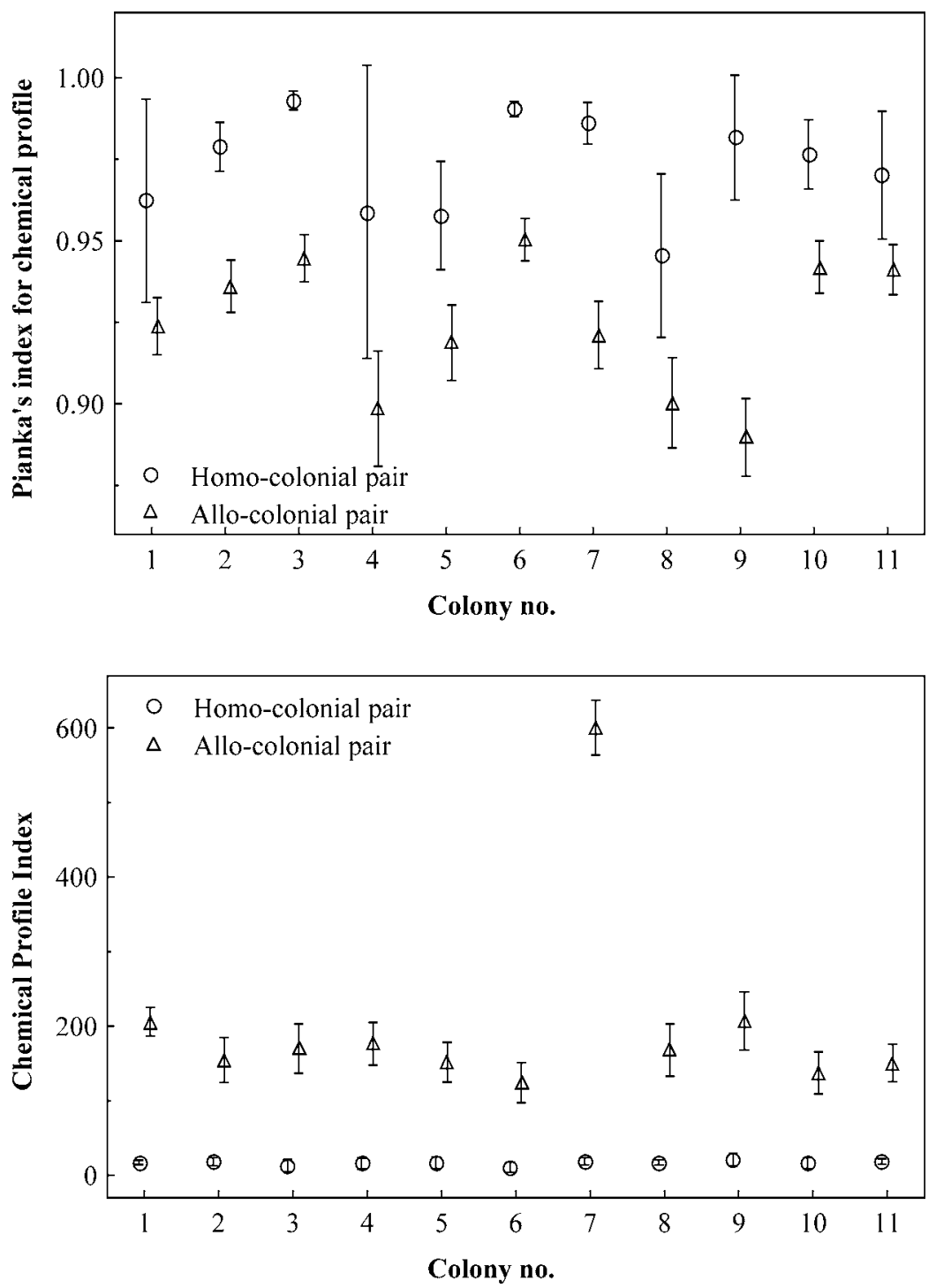

Fig. 4. Pianka's index (A) and Chemical Profile Index (B) for the cuticular hydrocarbon proportions between workers of a given colony pair. Marks designate means and bars SEM. 
Chemical Profile Index, although regression coefficients were negative in the laboratory and positive in the field colonies (Fig. 5). Likewise, the Aggression Index $(y)$ was significantly regressed on the Chemical Profile Index $(x)$, but the correlation coefficients were smaller: $y=4.157+7.151 x$, $r^{2}=0.303, F_{1,119}=51.84, P<0.001$ (laboratory), and $y=3.312+2.542 x$, $r^{2}=0.499, F_{1,64}=54.73, P<0.001$ (field), respectively. Hence, the PCA Behavioral Index could quantify worker behaviors better than the Aggression Index.

In the plot of the PCA Behavioral Index and Chemical Profile Index of field colonies, two pairs (2-3 and 5-12 in Fig. 5), fell distantly from the other inter-colony pairs but rather closely to the intra-colony pair on the ordinate axis, indicating that these pairs formed mother-fissional nests. Thus, it is possible that a combination of PCA Behavioral and Chemical Profile Indices can be used to identify colonies that may have been joined originally.

\section{DISCUSSION}

Our studies revealed significant correlation of both the PCA Behavioral and classical Aggression Indices with the Chemical Profile Index for laboratory colonies. The results support the graded response model for recognition in A. senilis. The PCA Behavioral Index better quantified recognition behaviors than did the classical Aggressive Index. This should be attributed to the behavioral categories that were included in the former but not in the latter: resting, antennal contact, grooming, and the aggression latency. In particular, the last category is difficult to include in the Aggression Index.

The PCA Behavioral Index might be useful in studying workers of other ant species, especially those that perform fissioning and those that rarely release aggressions against non-nestmates. Cataglyphis spp. workers, for example, when separated from the same nest increase the frequency of antennal contacts with time, but rarely become seriously aggressive each other (Dahbi et al., 1999; Lahav et al., 2001). Similarly, Camponotus fellah workers increase trophallaxis with time after being separated from the main colony (Boulay and Lenoir, 2001). For these ants, the Aggression Index may not clearly distinguish allo-colonial workers from homo-colonial ones, unless grooming is given very high scores. Likewise, the Aggression Index might be less powerful for ants that perform fission as we found in A. senilis.

In the initial period after fissioning, ant workers increase antennal contacts or groomings, not behaving aggressively towards those of the mother 

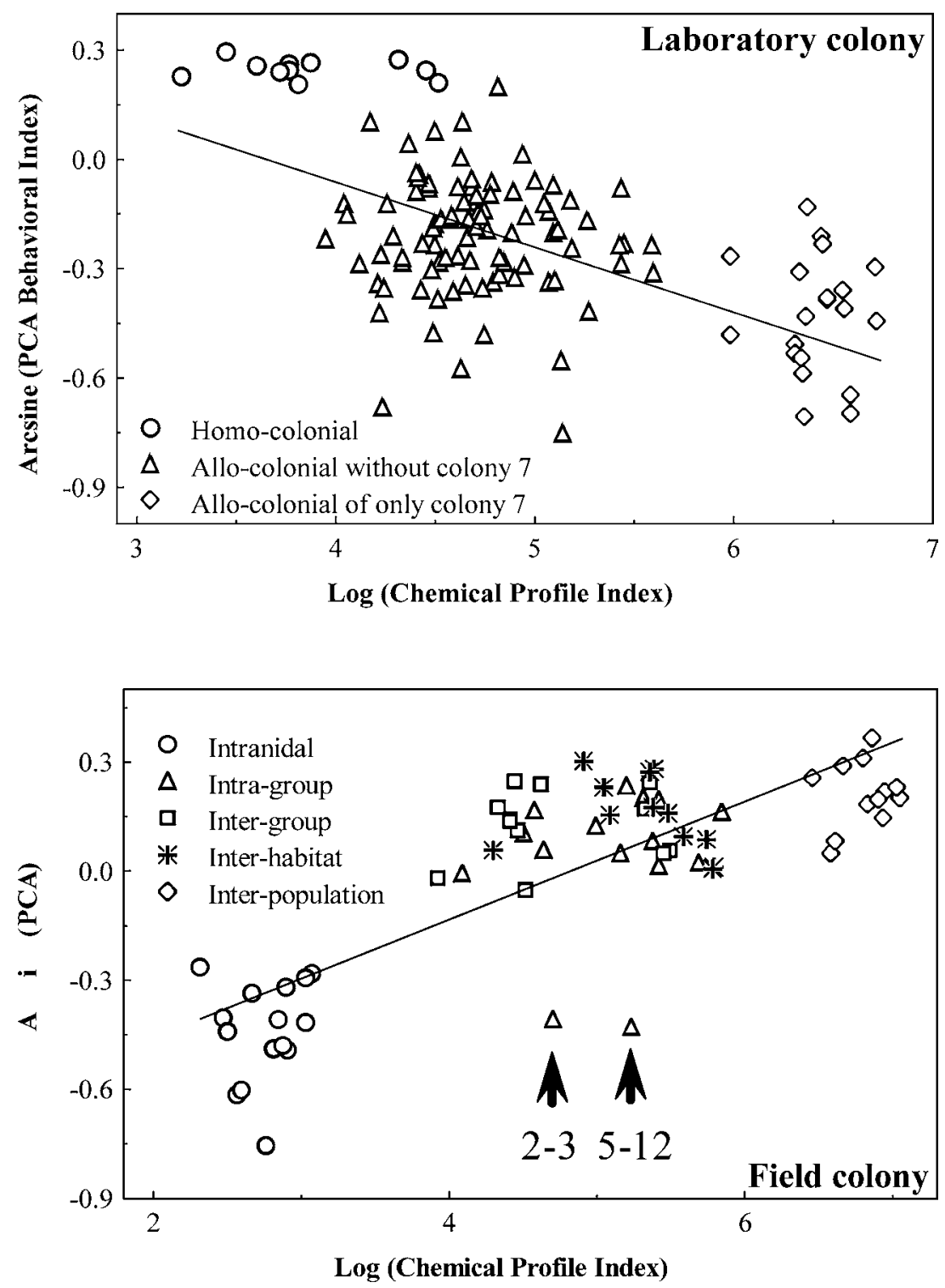

Fig. 5. Arcsine transformed PCA Behavioral Index plotted against log-transformed Chemical Profile Index of laboratory- (upper) and field-collected (lower) colonies. Arrows indicate the nest pairs of field-collected nests that were suspected as recently budded nests. The solid line designates a regression line in each. Regressions for the laboratory- and field colonies are $y=0.598-0.164 x, r^{2}=0.331, F_{1,119}=58.75, P<0.001$, and $y=4.750+3.710 x, r^{2}=0.624, F_{1,64}=106.01, P<0.001$, respectively. 
nest. Over time, such transient behaviors are gradually substituted for aggressions (Lenoir et al., 2001a). The transient situation is smoothly scaled by the PCA Behavioral Index. It is important to note that frequencies of recognition behaviors may vary even between any given worker pairs (c.f. Whitehouse and Jaffé, 1995; Fénéron, 1996; Dahbi et al., 1997; Cassill and Tschinkel, 1999; Lahav et al., 1999; Nielsen et al., 1999; Boulay et al., 2000). Such variation was also observed in $A$. senilis, and this could have been caused in part by the age and/or tasks that workers had been engaged in (Table II). The PCA Behavioral Index detected the behavioral differences in the homo-colonial pairs better than the Aggression Index, while it was less sensitive to the increase of aggression in the allo-colonial pairs. Hence, the PCA Behavioral Index is more sensitive to worker behaviors among separated nests in the initial phase when their chemical profile is less differentiated (Lenoir et al., 2001a).

Discrimination between separated workers increases as cuticular hydrocarbon profiles diverge (Vander Meer et al., 1989; Kaib et al., 2000; Boulay and Lenoir 2001; Lenoir et al., 2001a). It is therefore likely that pairs which do not fit the PCA Behavioral/Chemical Profile Indices regression line could come from a recent fission. Two pairs we plotted (2-3 and 5-12 in Fig. 5) might be such a case of fissioning nests. It is not surprising to find evidence of recent fission, since this ant species makes budding nests in May-July (Ledoux, 1976), when we performed the collection. Although chemical profiles between these pairs were as different as those in other allo-colonial pairs, their behaviors were rather similar to those of the homo-colonial pairs. This suggests substances that were less variable may have determined the recognition behavior, while other minor substances changed their composition more rapidly without altering recognition patterns. The graded model responses in $A$. senilis makes it possible to estimate the degree of separation of any pair of colonies by comparing the PCA Behavioral Indices of the tested pair to those in homo- and allo-colonial pairs and plotting them against the Chemical Profile Index. Such analysis could also be used to find the duration of nestmate recognition after fission.

\section{ACKNOWLEDGMENTS}

This study was performed during the Ichinose's stay in France with a fellowship from the French Government. The National reserve of Doñana authorities gave the authorization to collect the ants. Mr. Arnold Fertin and Mr. Guileric Fraquet helped us to maintain ant colonies in the laboratory. We thank Dr. Alberto Tinaut of the University of Granada for identification of the ants. Miss Hannah Reynolds kindly edited our manuscript. 


\section{REFERENCES}

Beye, M., Neumann, P., Chapuisat, M., and Pamilo, P. (1998). Nestmate recognition and the genetic relatedness of nests in the ant Formica pratensis. Behav. Ecol. Sociobiol. 43: 6772.

Blomquist, G. J., and Howard, R. W. (2003). Pheromone biosynthesis in social insects. In Blomquist, G., and Vogt, R. (eds.), Insect Pheromone Biochemistry and Molecular Biology: The Biosynthesis and Detection of Pheromones and Plant Volatiles, Elsevier Academic Press, London, pp. 323-340.

Boulay, R., Hefetz, A., Soroker, V., and Lenoir, A. (2000). Camponotus fellah colony integration: Worker individuality necessitates frequent hydrocarbon exchanges. Anim. Behav. 59: $1127-1133$.

Boulay, R., Katzav-Gozansky, T., Hefetz, A., and Lenoir, A. (2004). Odour convergence and tolerance between nestmates through trophallaxis and grooming in the ant Camponotus fellah (Della Torre). Insectes Soc. 51:55-61.

Boulay, R., and Lenoir, A. (2001). Social isolation of mature workers affects nestmate recognition in the ant Camponotus fellah. Behav. Process 55:67-73.

Bourke, A. F. G., and Franks, N. R. (1995). Social evolution in ants. In Monographs in Behavior and Ecology, Princeton University Press.

Carlin, N. F., and Hölldobler, B. (1986). Nestmate and kin recognition in interspecific mixed colonies of ants. Science 222: 1027-1029.

Carlin, N. F., and Hölldobler, B. (1987). The kin recognition system of carpenter ants (Camponotus spp.). II. Larger colonies. Behav. Ecol. Sociobiol. 20:209-217.

Cassill, D. L., and Tschinkel, W. R. (1999). Information flow during social feeding in ant societies. In Detrain, C., Deneubourg, J. L., Pasteels, J. (eds.), Information Processing in Social Insects, Birkhauser Verlag, Basel, pp. 69-81.

Chen, J. S. C., and Nonacs, P. (2000). Nestmate recognition and intraspecific aggression based on environmental cues in argentine ants (Hymenoptera: Formicidae). Ann. Entomol. Soc. Am. 93: 1333-1337.

Crozier, R. H., and Dix, M. (1979). Analysis of two genetic models for the innate components of colony odor in social Hymenoptera. Behav. Ecol. Sociobiol. 4:217-244.

Dahbi, A., Cerdá, X., Hefetz, A., and Lenoir, A. (1996). Social closure, aggressive behavior, and cuticular hydrocarbon profiles in the polydomous ant Cataglyphis iberica (Hymenoptera, Formicidae). J. Chem. Ecol. 22: 2173-2186.

Dahbi, A., Cerdá, X., Hefetz, A., and Lenoir, A. (1997). Adult transport in the ant Cataglyphis iberica: A means to maintain a uniform colonial odour in a species with multiple nests. Physiol. Entomol. 22: 13-19.

Dahbi, A., Hefetz, A., Cerdá, X., and Lenoir, A. (1999). Trophallaxis mediates uniformity of colony odor in Cataglyphis iberica ants (Hymenoptera, Formicidae). J. Insect Behav. 12: 559-567.

Dahbi, A., and Lenoir, A. (1998). Nest separation and the dynamics of the Gestalt odor in the polydomous ant Cataglyphis iberica (Hymenoptera, Formicidae). Behav. Ecol. Sociobiol. 42: 349-355.

de Biseau, J.-C., Passera, L., Daloze, D., and Aron, S. (2004). Ovarian activity correlates with extreme changes in cuticular hydrocarbon profile in the highly polygynous ant, Linepithema humile. J. Insect Physiol. 50:585-593.

Fénéron, R. (1996). A new ethological test to study nestmate recognition in adult ants. Insectes Soc. 43: 131-135.

Hefetz, A., Errard, C., Chambris, A., and Le Negrate, A. (1996). Postpharyngeal gland secretion as a modifier of aggressive behavior in the myrmicine ant Manica rubida. J. Insect Behav. 9: 709-717.

Hughes, W. O. H., Howse, P. E., and Goulson, D. (2001). Mandibular gland chemistry of grass-cutting ants: Species, caste, and colony variation. J. Chem. Ecol. 27: 109124. 
Kaib, M., Eisermann, B., Schoeters, E., Billen, J., Franke, S., and Francke, W. (2000). Taskrelated variation of postpharyngeal and cuticular hydrocarbon compositions in the ant Myrmicaria eumenoides. J. Comp. Physiol. A 186: 939-948.

Krebs, C. J. (1989). Ecological Methodology, Harper Collins, New York.

Lahav, S., Soroker, V., and Hefetz, A. (1999). Direct behavioral evidence for hydrocarbons as ant recognition discriminators. Naturwissenschaften 86: 246-249.

Lahav, S., Soroker, V., Vander Meer, R. K., and Hefetz, A. (2001). Segregation of colony odor in the desert ant Cataglyphis niger. J. Chem. Ecol. 27: 927-943.

Ledoux, A. (1971). Un nouveau mode de bouturage de société chez la fourmi Aphaenogaster senilis Mayr. C. R. Acad. Sci. Paris 273: 83-85.

Ledoux, M. A. (1976). Bourturage expérimental de colonie chez la fourmi Aphaenogaster senilis Mayr. C. R. Acad. Sci. Paris 283: 1061-1063.

Lenoir, A., Cuisset, D., and Hefetz, A. (2001a). Effects of social isolation on hydrocarbon pattern and nestmate recognition in the ant Aphaenogaster senilis (Hymenoptera, Formicidae). Insectes Soc. 48: 101-109.

Lenoir, A., D’Ettorre, P., Errard, C., and Hefetz, A. (2001b). Chemical ecology and social parasitism in ants. Ann. Rev. Entomol. 46: 573-599.

Lenoir, A., Fresneau, D., Errard, C., and Hefetz, A. (1999). Individual and colonial identity in ants: The emergence of the social representation concept. In Detrain, C., Deneubourg J. L., and Pasteels, J. (eds.), Information Processing in Social Insects, Birkhauser Verlag, Basel, pp. 219-237.

Lenoir, A., Hefetz, A., Simon, T., and Soroker, V. (2001c). Comparative dynamics of gestalt odour formation in two ant species Camponotus fellah and Aphaenogaster senilis (Hymenoptera: Formicidae). Physiol. Entomol. 26: 275283.

Lenoir, A., Malosse, C., and Yamaoka, R. (1997). Chemical mimicry between parasitic ants of the genus Formicoxenus and their host Myrmica (Hymenoptera, Formicidae). Biochem. Syst. Ecol. 25: 379-389.

Liang, D., Blomquist, G. J., and Silverman, J. (2001). Hydrocarbon-related nestmate aggression in the Argentine ant, Linepithema humile, following encounters with insect prey. Comp. Biochem. Physiol. B 129: 871-882.

Liang, D., and Silverman, J. (2000). "You are what you eat": Diet modifies cuticular hydrocarbons and nestmate recognition in the Argentine ant, Linepithema humile. Naturwissenschaften 87: 412-416.

Nielsen, J., Boomsma, J. J., Oldham, N. J., Petersen, H. C., and Morgan, E. D. (1999). Colonylevel and season-specific variation in cuticular hydrocarbon profiles of individual workers in the ant Formica truncorum. Insectes Soc. 46: 58-65.

Reeve, H. K. (1989). The evolution of conspecific acceptance thresholds. Am. Nat. 133: 407435.

Roulston, T. H., Buczkowski, G., and Silverman, J. (2003). Nestmate discrimination in ants: Effect of bioassay on aggressive behavior. Insectes Soc. 50: 151159.

Silverman, J., and Liang, D. (2001). Colony disassociation following diet partitioning in a unicolonial ant. Naturwissenschaften 88: 73-77.

Singer, T. L., Camann, M. A., and Espelie, K. E. (1992). Discriminant analysis of cuticular hydrocarbons of social wasp Polistes exclamans Viereck and surface hydrocarbons of its nest paper and pedicel. J. Chem. Ecol. 18: 785-797.

Soroker, V., Lucas, C., Simon, T., Hefetz, A., Fresneau, D., and Durand, J. L. (2003). Hydrocarbon distribution and colony odour homogenisation in Pachycondyla apicalis. Insectes Soc. 50: 212-217.

Soroker, V., Vienne, C., Nowbahari, E., and Hefetz, A. (1994). The post-pharyngeal gland as a "gestalt" organ for nestmate recognition in the ant Cataglyphis niger. Naturwissenschaften 81: $510-513$.

Stuart, R. J., and Herbers, J. M. (2000). Nest mate recognition in ants with complex colonies: Within- and between-population variation. Behav. Ecol. 11:676-685. 
Thomas, M. L., Parry, L. J., Allan, R. A., and Elgar, M. A. (1999). Geographic affinity, cuticular hydrocarbons and colony recognition in the Australian Meat ant Iridomyrmex purpureus. Naturwissenschaften 86: 87-92.

Vander Meer, R. K., Saliwanchik, D., and Lavine, B. (1989). Temporal changes in colony cuticular hydrocarbon patterns of Solenopsis invicta: Implications for nestmate recognition. J. Chem. Ecol. 15: 2115-2125.

Vander Meer, R. K., and Morel, L. (1998). Nestmate recognition in ants. In Vander Meer, M. D., Espelie, K., and Winston, M. L. (eds.), Pheromone Communication in Social Insects: Ants, Wasps, Bees and Termites, Westview Press, Boulder, pp. 79-103.

Whitehouse, M. E. A., and Jaffé, K. (1995). Nestmate recognition in the leaf-cutting ant Atta laevigata. Insectes Soc. 42:157-166. 